\title{
Effect of Process Parameters on Pulsed-Laser Repair of a Directionally Solidified Superalloy
}

\author{
Leijun Li · Andrew Deceuster · Chunbo Zhang
}

Received: 28 March 2012/ Accepted: 19 June 2012/Published online: 26 July 2012

(C) Springer Science+Business Media, LLC and ASM International 2012

\begin{abstract}
Directionally solidified nickel-based superalloy GTD-111 was repaired using pulsed Nd:YAG laser powder deposition (PLPD). A test matrix was created and tested to link deposit and defect formation to process parameters. Epitaxial solidification of the deposit was achieved. The grain size was uniform throughout multiple layers of deposit and appeared to be of cellular dendritic morphology. The crack formation is associated with the "stray" grains, which seem to be controlled by the geometry and overlap of the deposits. The formation of stray grains tended to be suppressed in deposits with shallow and wide profiles with smooth toe transitions into previous beads. Geometric discontinuity and formation of stray grains were found to contribute significantly to the formation of microfissures at the weld toes. Multiple pulses were found to remelt and heal the microfissures in the previous spot deposit. With optimized process parameters, crack-free, multiple-layered, deposits were achieved for tip repair (topdown orientation) of GTD-111 blades with René 80 and IN625 filler metals.
\end{abstract}

Keywords Superalloys $\cdot$ Joining $\cdot$ Process modeling · Microstructural examination

L. Li $(\bowtie) \cdot$ A. Deceuster · C. Zhang

Mechanical \& Aerospace Engineering,

Utah State University, Logan,

UT 84322-4130, USA

e-mail: leijun.li@usu.edu

\section{Introduction}

Laser powder deposition is finding more successful applications in repair of directionally solidified (DS) and singlecrystal superalloy blades. A persistent technical challenge is how to prevent the formation of stray grains and solidification microfissures [1-3]. It has now been established that stray grains - the grains whose growth orientations are significantly different from the matrix growth direction that result in large-angle grain boundaries-enhance hot cracking susceptibility in the deposit. The factors for stray grain formation are thought to be related with the crystal nucleation and growth conditions [4-6]. However, because of the small scale of laser deposit and fast transient processes during deposition, no direct experimental observation on conditions for stray grain formation has been made. Since solidification cracking in the deposit is governed by shrinkage thermal stresses and stray grains associated with temperature gradient, it was assumed that numerical simulations of the dynamic thermal field would provide insight into the conditions for stray grain formation, and subsequently hot cracking as influenced by the process parameters.

The objective of this article is to understand the relation of deposit geometry variations resulted from process parameters, including the deposit overlapping as an independent parameter, with deposition defects, such as stray grains and microfissures, resulted from transient thermal field. The distribution of temperature gradient along deposit boundaries, especially at critical positions (e.g., weld toes), are analyzed and explained. For the purposes of cracking prevention and deposition quality improvement, the predicted temperature gradient distributions have been correlated with the thermal stress concentration, and the stray grain formation to study the cracking tendency in multi-bead deposition format. The tendency of cracking occurrence is discussed 
based on its relation with thermal stress concentration and stray grain formation, which are determined by the temperature gradient field.

\section{Experimental Procedure}

A square wave pulsing Nd:YAG laser with arrangements to deliver the power through fiber optical cables to the work piece was used as the heat source. The average power maximum output is $50 \mathrm{~W}$ with a peak pulse power of $5 \mathrm{~kW}$. The optical head used in the studies had a focal length of $100 \mathrm{~mm}$. A combination inert gas shield cup and powder injection nozzle was designed and attached to the lens for enhanced argon shielding and injection of the powder into the weld pool. The powder injection nozzle was set to an angle of $45^{\circ}$ with an orifice opening of $1.5 \mathrm{~mm}$, with a set back of $8 \mathrm{~mm}$. A powder feeder was used for injecting the powder into the liquid pool. The flow rate of the powder feeder $(\mathrm{g} / \mathrm{s})$ was calibrated against the rotation speed of the feeding disk (rpm). The samples were prepared by wet-abrasive and wire EDM cutting from a fully annealed, DS, GTD-111 turbine blade. The samples were ground to remove material affected by the cutting process, polished with 180-grit paper, and cleaned with acetone prior to the deposition.

The repair deposition of the tip of GTD-111 turbine blades does not require as much strength as the other discussed defects and can be repaired using either René 80 or IN625 material. René 80 is the closest matching filler material to GTD-111 that is commercially available. The chemical compositions for GTD-111, René 80, and IN625 can be seen in Table 1. René 80 exhibits higher strength than IN625, but IN625 is more ductile and corrosion resistant, which could make IN625 better for tip refurbishment. The powder size used for deposition was 125-325 $\mu \mathrm{m}$. The powder output was held constant at $3 \mathrm{rpm}$, with an equivalent flow rate of $20 \mathrm{~g} / \mathrm{m}$. The pressure of the argon that carried the powder to the melt pool was held at a constant 35 psi. The travel direction of the laser and powder was similar to that of gas tungsten arc welding, where the powder was leading the laser. The powder was injected into the melt pool directly from the nozzle. The process efficiency required a laser spot size of $1 \mathrm{~mm}$ to improve the capture percentage of the powder being injected into the melt pool.

Microstructural characterization of the samples was carried out by cross-sectioning the samples on a wet abrasive saw. Following sectioning, the samples were mounted and polished up to 1200 grit. Samples were then diamond polished $0.1 \mu \mathrm{m}$ and etched using Marble's regent. The samples were inspected and photographed using a metallurgical microscope.
Table 1 Chemical composition (wt.\%) of test alloys

\begin{tabular}{|c|c|c|c|}
\hline Element & GTD-111 & $\begin{array}{l}\text { PRAXAIR } \\
\text { Ni138 (René 80) }\end{array}$ & $\begin{array}{l}\text { PRAXAIR } \\
\text { NI625 (IN625) }\end{array}$ \\
\hline $\mathrm{Al}$ & $2.8-3.2$ & 2.80 & 0.2 \\
\hline B & $0.01-0.02$ & 0.01 & $\ldots$ \\
\hline $\mathrm{C}$ & $0.08-0.12$ & 0.18 & $\ldots$ \\
\hline Co & $9.0-10.0$ & 9.66 & 0.1 \\
\hline $\mathrm{Cr}$ & $13.7-14.3$ & 14.09 & 22.0 \\
\hline $\mathrm{Cu}$ & $\ldots$ & 0.05 & $\ldots$ \\
\hline $\mathrm{Fe}$ & $\ldots$ & 0.05 & 2.5 \\
\hline Hf & $0.02-0.08$ & 0.10 & $\ldots$ \\
\hline $\mathrm{Mg}$ & $\ldots$ & 0.001 & $\ldots$ \\
\hline $\mathrm{Mn}$ & $\ldots$ & 0.10 & 0.3 \\
\hline Mo & $1.3-1.7$ & 4.03 & 9.0 \\
\hline $\mathrm{N}$ & $\ldots$ & 0.0049 & $\ldots$ \\
\hline $\mathrm{Nb}$ & $\ldots$ & 0.05 & $\ldots$ \\
\hline $\mathrm{O}$ & $\cdots$ & 0.01 & $\cdots$ \\
\hline $\mathrm{P}$ & $\ldots$ & 0.005 & $\ldots$ \\
\hline $\mathrm{S}$ & $\cdots$ & 0.0017 & $\ldots$ \\
\hline $\mathrm{Se}$ & $\ldots$ & 0.005 & $\ldots$ \\
\hline $\mathrm{Si}$ & $\ldots$ & 0.10 & 0.2 \\
\hline $\mathrm{Ta}$ & $2.5-3.1$ & 0.10 & 3.6 \\
\hline $\mathrm{Ti}$ & $4.8-5.1$ & 4.83 & 0.2 \\
\hline V & $\cdots$ & 0.05 & $\cdots$ \\
\hline W & $3.5-4.1$ & 3.91 & $\ldots$ \\
\hline $\mathrm{Zr}$ & $0.02-0.08$ & 0.06 & $\cdots$ \\
\hline $\mathrm{Ni}$ & Balance & Balance & Balance \\
\hline
\end{tabular}

\section{Results}

A typical single-bead René 80 deposit shows a fine ripple pattern on the surface, due to the pulsing of the laser, with spatter randomly stuck onto the surface, as seen in Fig. 1. The spatter consisted of partially melted powders from the nozzle coming into contact with the laser column, and from the expulsion of molten metal from the weld pool due to the collapsing of the plasma plume. The spatter was mostly superficial and easily removed, while those that remained were melted by subsequent layers. The remelted spatter could not be detected in the microstructure and was considered not to interfere with the process. Figure 2 shows an example of a two-layer deposit of IN625 powder on GTD111 top-down orientation for tip repair. After grinding off the surface roughness, dye-penetrant tests were conducted, and the deposit was found to be defect-free, without any pre- or post-deposition heating.

Figure 3 shows a microstructure of a deposit-substrate interface. Metallurgical bonding is obtained. The microstructure shows a minimal heat-affected zone (HAZ) in the substrate, in which the gamma prime and bulky carbides appear to retain their original as-cast morphology. The 




Fig. 1 A single-track pulsed-laser deposit of René 80 powder on GTD 111 material

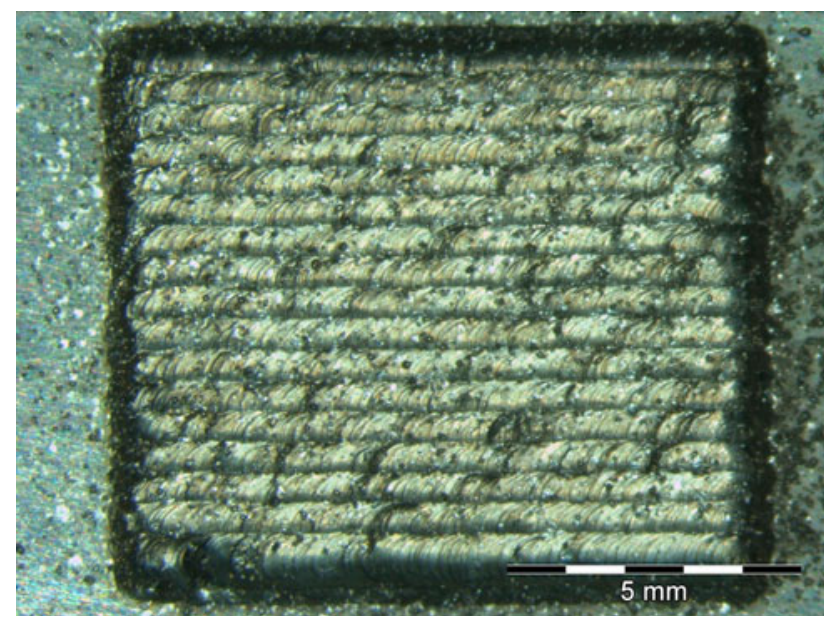

Fig. 2 Two-layer laser deposit of IN625 powder on GTD-111 topdown orientation for tip repair

substrate also provided the retained $\mathrm{M}_{23} \mathrm{C}_{6}$ carbides observed in the deposits. The time spent above the substrate melting temperature was not sufficient for the carbides to melt or dissolve into solution. It is hypothesized that the substrate material surrounding the carbide becomes liquid while the carbide remains solid. The high solidification rate does not allow the carbides to go into solution but instead retain their morphology and position in the substrate upon re-solidification. The distribution of carbides in the deposits does not extend far beyond the fusion interface and never past the original base metal boundary, suggesting that they do not migrate during the laser processing. The lack of carbide migration would also suggest that there was limited mixing during the liquid state of the process. The lack of mixing was also shown by the

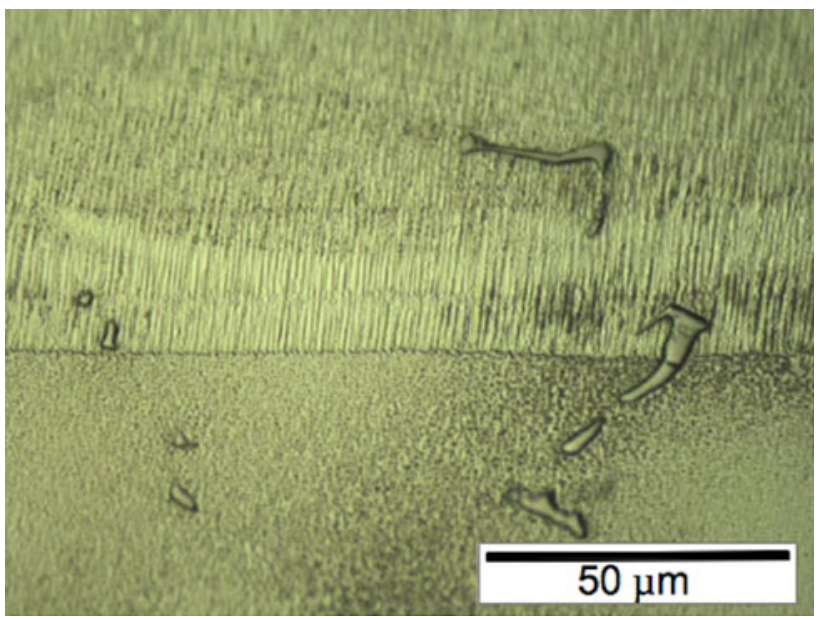

Fig. 3 Microstructure of the deposit-substrate interface. Metallurgical bonding is obtained. The PLPD process has a minimal HAZ in the substrate, in which the gamma prime and bulky carbides retain their original morphology

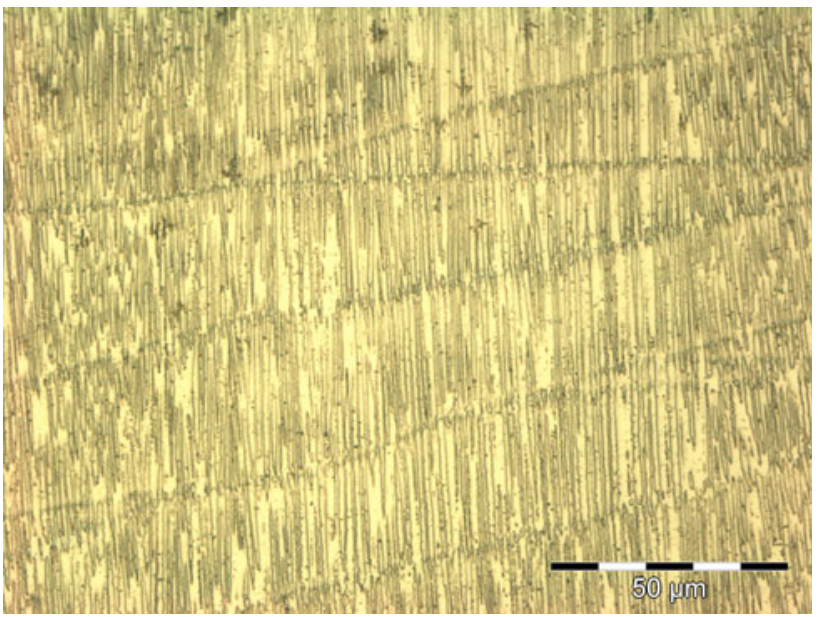

Fig. 4 The directionality of the deposit can be seen through multiple pulses and layers

retaining of the unmixed zones in which the substrate was not given ample time to mix with the molten pool. Similar to the unmixed zone, the retention of the $\mathrm{M}_{23} \mathrm{C}_{6}$ carbides did not lead to the nucleation of stray grains in the first layer of the deposit. In multilayer deposition, continued directional growth of the dendrites can be obtained, as shown in Fig. 4.

The directionality of the deposits could be interrupted by formation of stray grains, grains that do not have the same orientation as the surrounding matrix. Stray grains were observed in every layer of some samples, with most stray grains confined to the second or higher layers. The formation of stray grains in the first layer was rare, and these grains tended to form around the toes of overlapping beads. In subsequent layers, the formation of stray grains was 
observed at the toes of overlapping beads as well. The flat-bottomed, thin-layered deposition was either free of or contained a smaller number of stray grains. Therefore, the shape and the deposition sequence of the deposit were identified as the key factors controlling the formation of stray grains.

Although stray grains did not necessarily lead to microfissuring, fissuring was always associated with a stray grain in this study. While no macroscale cracks (arbitrarily defined as cracks longer than $1 \mathrm{~mm}$ ) were observed in the deposits, microfissures (difficult to see without magnification) shorter than $0.5 \mathrm{~mm}$ have been observed in most of the tested multilayer deposits. In Fig. 5, microfissures in the second layers of the deposit are found to be exposed to the surface, but not to extend down into the first layer. The arrow in the figure points to the fusion boundary. In the substrate material below the fusion boundary, the dark features are carbides and porosity in the base metal. In the deposit above the fusion boundary, the dark spherical features are porosity in the deposit. After etching, the microfissures are found to be associated with dark-etching stray grain structures, and almost all fissures tend to originate from the toe of a previous deposit bead. The three toes shown in Fig. 6 all have stray grains and microfissures. Although a positive identification of stray grains requires orientation imaging microscopy (IOM), previous studies, such as Anderson et.al. [7], have shown that the darketching grains coincide with strain grains identified via OIM. This is not surprising, because under a given etching condition for optical metallography, cross-sectioned stray grains would expose a crystal plane other than the matrix crystal plane to the etching reagent. Different planar



Fig. 5 Cross-sectional view of the microfissures in René 80 deposited top-down to GTD-111 tip. More microfissures seem to form in the top layer in this as-polished view. Arrow indicates the location of the fusion boundary between the deposit and the substrate densities between the exposed stray grain and the matrix would result in a contrast after etching.

There is plenty of evidence to support the generalization that a weld toe is the preferred location for heterogeneous grain nucleation and growth in DS superalloys, which leads to the formation of "stray grains". Figure 7 shows one example of the collocation of stray grains and weld toe. In this top-down view of a two-layer René 80 deposit on GTD-111 tip repair, the stray grains tend to form along the weld toe line where two deposit beads intersect. The microfissures almost exclusively form along the grain boundaries of these stray grains. The association of microfissuring with the weld toe is not surprising, because



Fig. 6 The same field shown in Fig. 5, etched to show the relative location of microfissures to deposit microstructure. The microfissure $(A)$, located in the first layer, has been partially remelted and healed by the overlapping pulse. Microfissures in the top layer formed from the weld toes (indicated by letter $T$ ) of the underneath deposits, and are associated with dark-etched stray grains

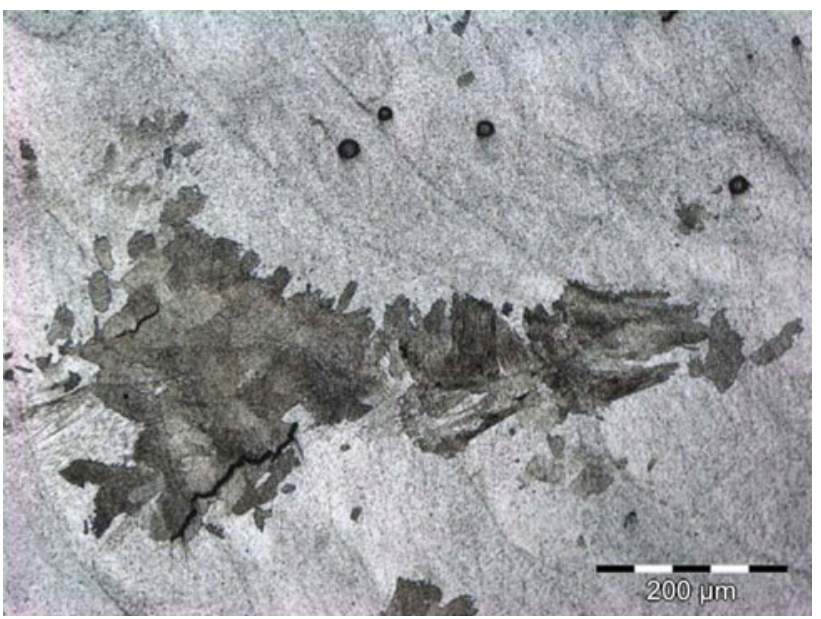

Fig. 7 Top-down view of a two-layer René 80 deposit on GTD-111 tip repair. The stray grains tend to form along the weld toe line where two deposit beads meet 
the geometric discontinuity at the weld toe may provide a local stress concentration. If other conditions are the same, higher stressed regions will most likely become the weakest link for cracks to form during weld cooling. In the present case, a major factor that sensitizes the microstructure for cracking is associated with the stray grains. The misalignment between the stray grain and the surrounding matrix means the grain boundaries of the stray grain will be large-angle grain boundaries. These large-angle boundaries tend to attract more elemental segregation at high temperatures, and are much weaker than the interdendritic small-angle boundaries within the surrounding matrix $[8,9]$. These characteristics of the stray grain boundaries will make hot-cracking more likely for a given thermal stress condition.

In addition to significantly decreasing the crack tendency by minimizing the heat input, pulsed laser deposition has another beneficial effect in controlling the propagation of microfissures. Figure 8 shows a top-down view of a René 80 deposit. The ripple marks outline each individual pulse deposit. This micrograph shows how two microfissures were healed by the fourth pulse counting from the right. The dark regions associated with the fissures are stray grains that etched darker than the surrounding material. A likely mechanism for the healing is remelting, which is supported by the fact that not only the fissure but also stray grains are cut short. The depth of a microfissure is not deeper than the weld pool also indicates that the cracking type is clearly a solidification hot cracking.

Results also show the effect of bead spacing or overlapping on stray grain and microfissure formation. The effect of overlapping was first noticed in the single bead

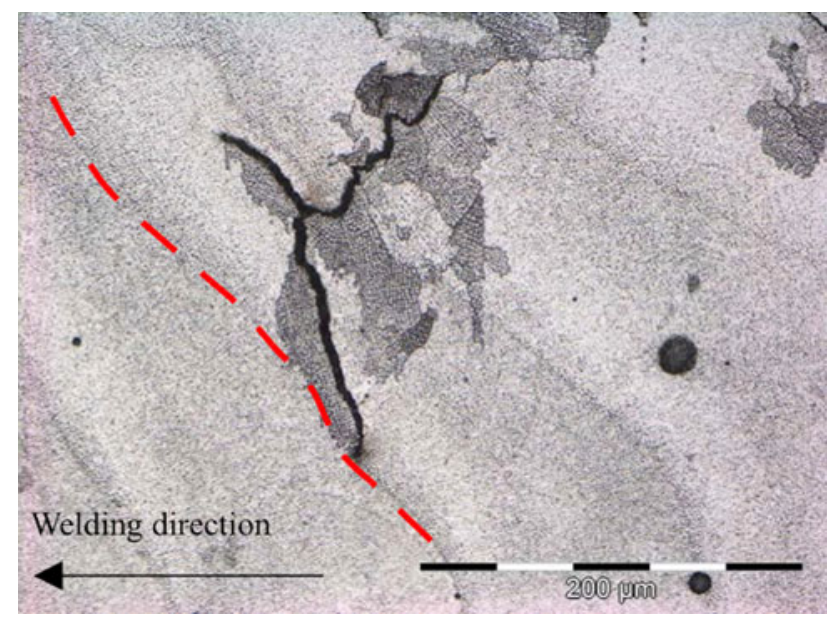

Fig. 8 Top-down view of microfissures restricted by the subsequent pulse. The microfissures formed along the large-angle grain boundary between the dark-etched grain and the substrate of the deposit. The ripple lines produced by multiple pulses are apparent. Note the microfissure is melted by the pulse marked by the dashed line experiments with the percentage of overlap of each pulse. It was observed that there were a maximum and minimum range in which the overlapping should reside, otherwise defects were noticed. The spacing between beads that was used for the experiments were $0.5,0.75,1.0$, and $1.25 \mathrm{~mm}$. Both IN625 and René 80 powder types were used in the overlap pattern study. Using the same shape of deposition, $0.75 \mathrm{~mm}$ overlap was found to be crack-free, while all other overlap values produced stray grains and microfissures.

\section{Discussion}

The results discussed above indicate that the formation of stray grains and microfissures is not random, but rather is governed by the transient thermal and stress fields. Since the deposition size is too small for experimental measurements of the variations in temperature and thermal strains during deposition, a three-dimensional coupled-field thermomechanical model was developed to provide additional information about the material during solidification. This model, recently published elsewhere [10], includes process parameters on overlapping and bead geometry, to simulate the multi-bead PLPD process applied to DS Ni-based turbine blade repair, using the ANSYS ${ }^{\circledR}$ code and element re-activation technology. The simulated transient temperature gradient and thermal stress results are summarized in Fig. 9. The tendency of stray grain formation can be

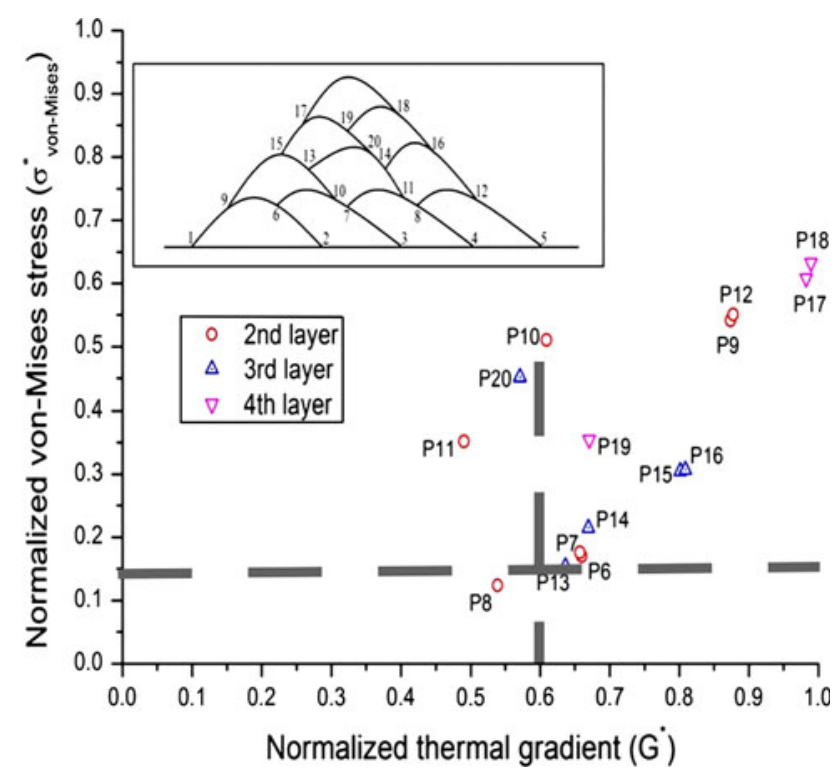

Fig. 9 The numerical model predicted that the upper left quadrant (that contains points $\mathrm{P} 10, \mathrm{P} 11$, and $\mathrm{P} 20$ ) is the most likely region to form microfissures, where thermal gradient is low to promote stray grain, and thermal stresses are high to enhance crack opening (based on [7]) 

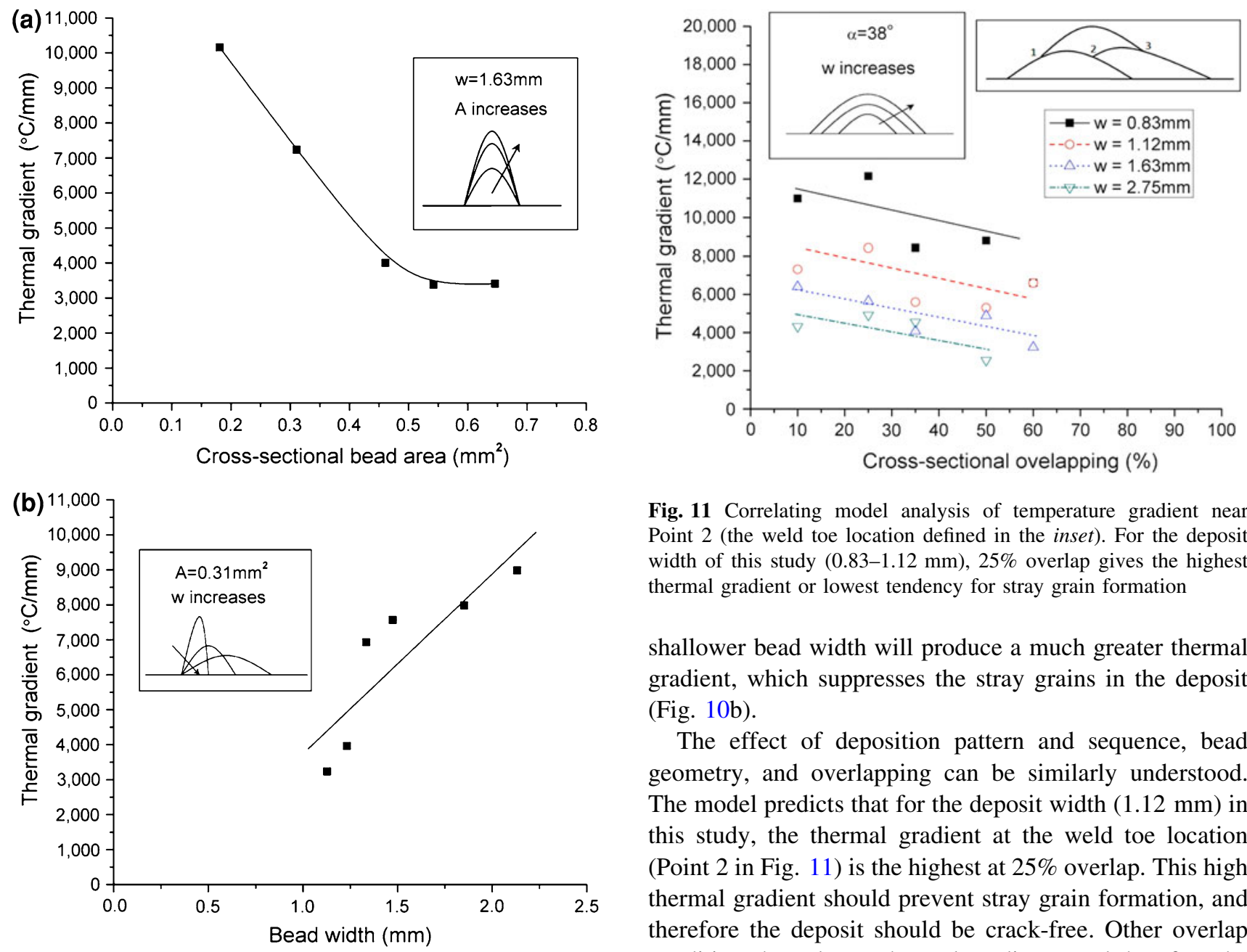

Fig. 11 Correlating model analysis of temperature gradient near Point 2 (the weld toe location defined in the inset). For the deposit width of this study $(0.83-1.12 \mathrm{~mm}), 25 \%$ overlap gives the highest thermal gradient or lowest tendency for stray grain formation

shallower bead width will produce a much greater thermal gradient, which suppresses the stray grains in the deposit (Fig. 10b).

The effect of deposition pattern and sequence, bead geometry, and overlapping can be similarly understood. The model predicts that for the deposit width $(1.12 \mathrm{~mm})$ in this study, the thermal gradient at the weld toe location (Point 2 in Fig. 11) is the highest at 25\% overlap. This high thermal gradient should prevent stray grain formation, and therefore the deposit should be crack-free. Other overlap conditions have lower thermal gradients, and therefore the

Fig. 10 Model predicted effect of cross-sectional area of deposit for a given width (a) and effect of deposit width for a given crosssectional area on thermal gradient of deposits (b). Wider and thinner deposits promote higher thermal gradient, and suppress stray grain formation

estimated by the temperature gradient, $G$. A greater $G$ leads to a smaller volume fraction of equiaxed dendrites, and therefore prevents the formation of the stray grains for a given bead shape [11]. In Fig. 9, the numerical model predicted that the upper left quadrant is the most likely region to form microfissures, where thermal gradient is low to promote stray grain, and thermal stresses are high to enhance crack opening. This theoretical prediction was verified by experimental temperature measurements and microfissure observations [10].

It was observed in this study that flat-bottomed, thin deposits are less likely to form stray grains; the thermomechanical model provides a theoretical explanation. For a given deposit width, a smaller, flat-bottomed, cross-sectional area will produce a much greater thermal gradient, which suppresses the stray grains in the deposit (Fig. 10a). Similarly, for a given cross-sectional area, a wider and deposits may see stray grains and microfissures. This prediction is verified by the experimental observations. In Fig. 12, the 25\% transverse overlap is shown to have produced a crack-free deposit, while other overlap values have produced stray grains and microfissures in the deposits.

\section{Conclusions}

Geometric discontinuity and formation of stray grains were found to contribute significantly to the formation of microfissures at the deposit toes. Bead geometry variations are influenced by laser deposition process parameters. If other conditions are kept the same, smaller deposition cross-sectional area increases crack resistance, at the cost of decreasing the process efficiency. For a given deposition cross-sectional area, a wider bead is suggested to improve the deposition quality by adjusting process parameters. In multi-bead, multi-layer deposition, the bead overlapping should be cautiously selected due to its effect on temperature gradient. There exists an optimum overlapping 
Fig. 12 The different percentage of overlap can be seen in the picture grid. The major defects are seen in the 75 , 50 , and $10 \%$ overlap, while $25 \%$ overlap is crack-free and straygrain free
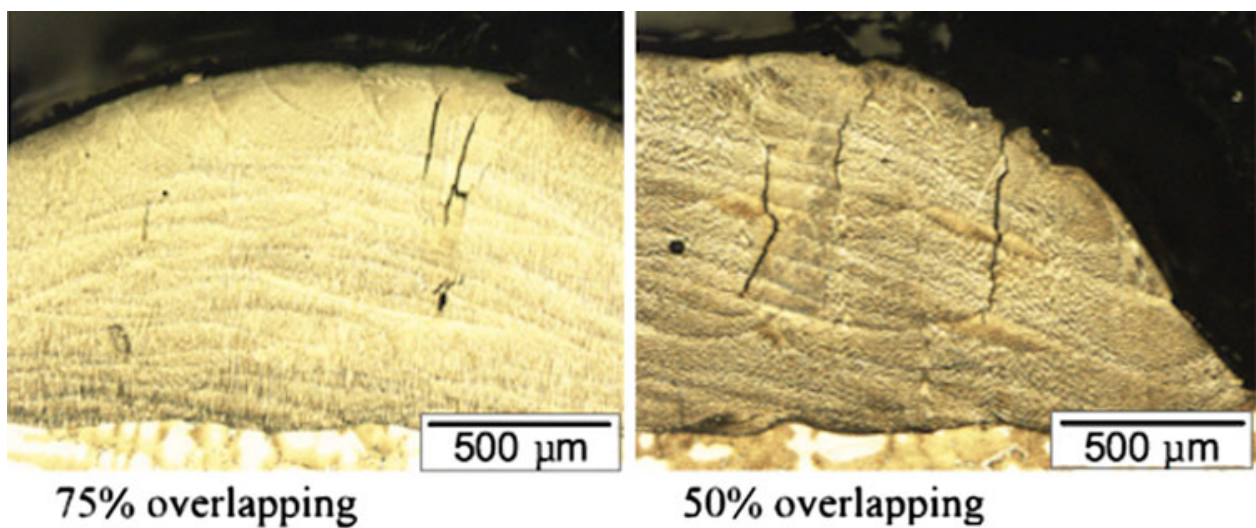

$75 \%$ overlapping

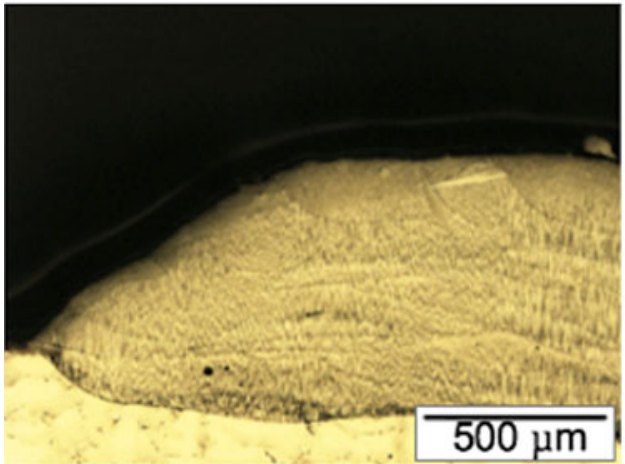

$25 \%$ overlapping

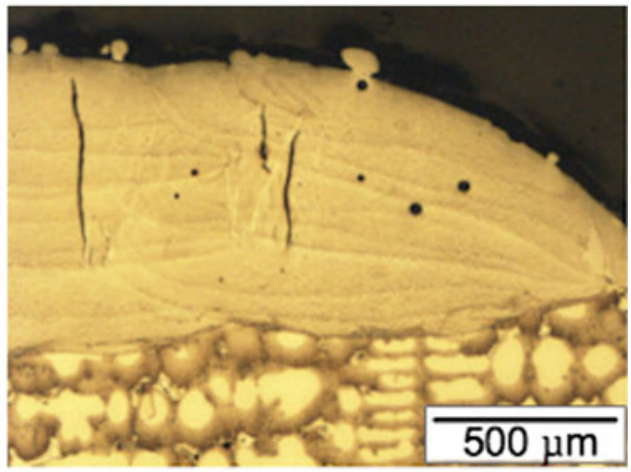

$10 \%$ overlapping percentage that reduces the temperature gradient at bead boundaries, which enhances stray grain formation. For the test conditions reported in this article, that optimum overlap is near $25 \%$. With optimized processes parameters, crack-free, multiple-layer, deposits were achieved for tip repair (top-down orientation) of GTD-111 buckets with René 80 and IN625 filler metals.

Acknowledgment The financial support from the Welding Research Council (WRC) and American Welding Society (AWS) Fellowship to Andrew Deceuster was gratefully acknowledged.

\section{References}

1. Y.P. Kathuria, Some aspects of laser surface cladding in the turbine industry. Surf. Coat. Technol. 132, 262-269 (2000)

2. T. Peters, W. Jahnen. Steam turbine leading edge repair by Stellite laser cladding. Proceedings of EPRI ST7, (CD-ROM), 2002

3. W. Liu, J. DuPont, Effects of melt-pool geometry on crystal growth and microstructure development in laser surface-melted superalloy single crystals. Mathematical modeling of single-crystal growth in a melt pool (part 1). Acta Mater. 52, 4833-4847 (2004)

4. W. Liu, J. DuPont, Effects of substrate crystallographic orientations on crystal growth and microstructure development in laser surface-melted superalloy single crystals. Mathematical modeling of single-crystal growth in a melt pool (part 2). Acta Mater. 53, 1545-1558 (2005)

5. L. Li, Repair of directionally solidified superalloy GTD-111 by laser-engineered net shaping. J. Mater. Sci. 41, 7886-7893 (2006)

6. J. Vitek, The effect of welding conditions on stray grain formation in single crystal welds-theoretical analysis. Acta Mater. 53, 53-67 (2005)

7. T. Anderson, J. DuPont, T. DebRoy, Stray grain formation in welds of single-crystal Ni-base superalloy CMSX-4. Met. Mater. Trans. A 41A, 181-193 (2010)

8. D.A. Porter, K.E. Easterling, Phase Transformations in Metals and Alloys (Chapman \& Hill, London, 1992), p. 228

9. M. de Hass, JThM de Hosson, Grain boundary segregation and precipitation in aluminum alloys. Scripta Mater. 44, 281-286 (2001)

10. C. Zhang, L. Li, A. Deceuster, Thermomechanical analysis of multi-bead pulsed laser powder deposition of a nickel-based superalloy. J. Mater. Process. Technol. 211, 1478-1487 (2011)

11. J.D. Hunt, Steady state columnar and equiaxed growth of dendrites and eutectic. Mater. Sci. Eng. 65, 75-83 (1984) 